\title{
A Fetal Fatality Caused by Premature Foramen Ovale Closure During Pregnancy
}

Giuseppe De Bernardo $^{1 *}$, Antonio Saggese ${ }^{2}$, Maria Svelto ${ }^{3}$, Desiree Sordino ${ }^{3}$ and Maurizio Giordano ${ }^{4}$

${ }^{1}$ Division of Pediatrics Neonatology and NICU, Ospedale Buon Consiglio Fatebenefratelli, Naples, Italy

${ }^{2}$ Institute of Legal Medicine, Second University of Naples, Napoli, Italy

${ }^{3}$ Department of Emergency, A.O.R.N. Santobono-Pausilipon, Napoli, Italy

${ }^{4}$ Faculty of Medicine, Federico II University, Naples, Italy

"Corresponding author: De Bernardo G, MD, Division of Pediatrics Neonatology and NICU, Ospedale Buon Consiglio Fatebenefratelli, Naples, Italy, Tel: +39-335 744 1303; E-mail: pinodebtin@ gmail.com

Received: March 14, 2020; Accepted: March 25, 2020; Published: March 31, 2020

\begin{abstract}
Premature closure of the foramen ovale may occurs at any time during pregnancy, diagnosis is difficult. We describe a premature closure of foramen ovale detected by autopsy. Color Doppler or the use of directional enhanced flow can be helping for caregivers to make timely decisions about delivery mode.
\end{abstract}

Keywords: Cardiovascular; Cerebral edema; Echocardiography; Fetal death; Pregnancy

\section{Introduction}

The foramen ovale (FO) is an important prenatal shunt between the right and left heart. The flap of the FO is a rudiment of the septum primum and acts as a one-way valve. In the fetus, this rudiment allows the $80 \%$ of the total volume of oxygenated blood that returns from the placenta to bypass partially the pulmonary circulation. Postnatally, the FO is functionally closed by higher blood pressure in the left atrium as the left atrium starts receiving blood from lungs. After the premature closure or restriction of FO, the blood flow increases into the right ventricle causing a reduced or absent flow to the left heart. Any resultant morphologic abnormalities such as right heart enlargement, right heart failure with fetal hydrops until intrauterine death depends on the time of onset and the severity of FO constriction. The etiology is unknown. The incidence ranges from 0.2 to $1 \%$ depending on the study population [1-2]. Premature closure of FO is known to be associated with right heart failure, resulting in fetal hydrops and eventually fetal death. Thus, the diagnosis is often made by post mortem examination. Furthermore, this premature closure of the FO may occur at any time during pregnancy and the diagnosis is difficult. We present 1 cases of isolated FO closure without fetal hydrops, left heart defect or supraventricular tachycardia.

Citation: De Bernardo G, Saggese A, Svelto M, et al. A Fetal Fatality Caused by Premature Foramen Ovale Closure During Pregnancy. Clin Case Rep Open Access. 2020;3(1):142. 


\section{Case Report}

A 30-year-old woman arrived to the maternity ward at 39 weeks of gestation age reporting that she could no longer feel fetal movement. A fetal routine ultrasonography examination at 38 weeks' gestation had not shown pathological findings in cardiac ventricle size, function, or aortic arch anatomy. Furthermore, there were no other cardiac anomalies. The mother has undergone cardiotocography. Cardiotocography showed no fetal heartbeat. The fetal autopsy showed premature foramen ovale closure with no other cardiac abnormalities, although there was minimal pericardial effusion. The brain ventricles had collapsed because of a massive cerebral edema. There was no evidence of changes in placental morphology, which was compatible with the physiological phase of the third trimester of gestation. Death was caused by premature FO closure (FIG. $1)$.

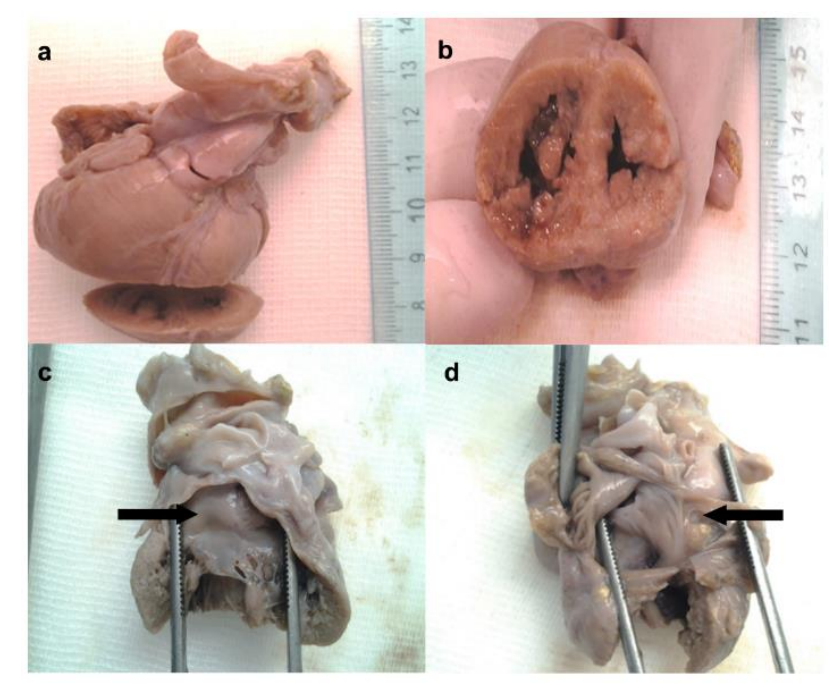

FIG. 1. (a) The heart has a normal shape and volume. (b). There was no evidence of abnormalities in the anterior chambers of the heart. (c-d) Autopsy results showing a membranous covering over the foramen ovale (arrows), leading to a pathologic diagnosis of premature foramen ovale closure.

\section{Discussion}

Interatrial communication in the fetal heart is dependent on the FO, which arises from the incomplete closure of the septum secundum. This natural shunt provides most of the left ventricular inflow that supplies the cerebral and coronary vascular beds with adequately oxygenated blood [1-2]. Premature closure of the foramen ovale can occur as an isolated defect or in association with other congenital and cardiovascular defects, such as aortic valvular atresia/stenosis, anomalous pulmonary venous return, and transposition of the great arteries [3]. FO closure can cause arrhythmia, right heart failure and congestion, pericardial and pleural effusion, ascites, and non-immune hydrops. The diagnosis of premature FO closure can be determined in utero using echocardiography [4]. Conventional color Doppler or directional enhanced flow imaging can lead to an early diagnosis to facilitate parent counseling and birth timing plans [4-5]. Criteria for a diagnosis can include a FO diameter less than $2 \mathrm{~mm}$ with a Doppler velocity greater than $120 \mathrm{~cm} / \mathrm{s}$ or a foramen ovale diameter less than $3 \mathrm{~mm}$ with a Doppler velocity-measured gradient of greater than $5 \mathrm{mmHg}$ [4]. Understanding color Doppler results, it is important to determine if the blood pressure is very high or very low. Traditional color flow maps are limited in displaying low velocity blood flow through the foramen ovale. D-eFLOW is a new technology developed by Aloka and it allowed to image dynamic blood 
flows. It is characterized by a widened bandwidth of ultrasound transmitter/receiver and a review about the processing method, resulting in a new blood flow-imaging mode with high spatial and temporal resolution. D-eFLOW can display the details about blood flow with a very high resolution optimizing the sequence transmission/reception and color-coding settings, depending on the purpose of the test. Compared with conventional blood flow display methods, however, D-eFLOW shows enhanced spatial and time resolution for greater details [4]. In fetuses with premature closure or restriction of the FO, it is very critical to choose the delivery time. The fetuses of our patients had premature closure or restriction of the FO during the third trimester. Follow-up fetal echocardiography with conventional color Doppler or D-eFLOW may help pregnant women decide on preterm delivery. Gupta et al [6] have found that the fetuses only with premature closure of FO have a good prognosis. Lin Liu et al [7] reported in their studies that the fetuses without other malformations, hydrothorax and ascites but only premature closure of FO would have a good prognosis.

We reported in TABLE 1 the cases with a premature closure of the FO without other malformations. Considering our cases, lifesaving treatments may be premature labor. However, revisions and further research are needed to determine the times and the techniques to be used to provide appropriate prevention.

TABLE 1. The cases with a premature closure of the FO without other malformations.

\begin{tabular}{|c|c|c|c|c|c|c|}
\hline References & $\mathbf{N}^{\circ}$ cases & $\begin{array}{l}\text { GA at } \\
\text { prenatal } \\
\text { diagnosis }\end{array}$ & Prenatal diagnostic tool & $\begin{array}{l}\text { GA at } \\
\text { Caesarian } \\
\text { section/sp } \\
\text { ontaneous } \\
\text { vaginal } \\
\text { delivery }\end{array}$ & Follow up & Status \\
\hline $\begin{array}{l}\text { Hagen A et al. } \\
2005 \text { [1] }\end{array}$ & 2 & $\begin{array}{l}35 \\
36\end{array}$ & $\begin{array}{l}\text { Cardiotocograms } \\
\text { Conventional color } \\
\text { Doppler }\end{array}$ & $\begin{array}{l}35 \mathrm{CS} \\
36 \mathrm{CS}\end{array}$ & $\begin{array}{l}\text { 6-months } \\
\text { 1-year }\end{array}$ & $\begin{array}{l}\text { Alive } \\
\text { Alive }\end{array}$ \\
\hline $\begin{array}{l}\text { Li YD et al. } \\
2013 \text { [3] }\end{array}$ & 2 & 38 & $\begin{array}{l}\text { conventional color } \\
\text { Doppler imaging, D- } \\
\text { eFLOW } \\
\text { conventional color } \\
\text { Doppler imaging, D- } \\
\text { eFLOW }\end{array}$ & $\begin{array}{l}38 \mathrm{SVG} \\
38 \mathrm{SVG}\end{array}$ & $\begin{array}{l}0 \text { day } \\
1 \quad \text { week } \\
\text { after birth }\end{array}$ & $\begin{array}{l}\text { Died } \\
\text { Alive }\end{array}$ \\
\hline $\begin{array}{l}\text { Lin Liu et al. } \\
2016[6]\end{array}$ & 16 & unknown & unknown & unknown & 30-60 days & Alive \\
\hline
\end{tabular}

\section{Abbreviations}

FO=Foramen ovale; D-eFLOW=Directional enhanced flow imaging; $\mathrm{cm} / \mathrm{s}=$ Centimeters to seconds; $\mathrm{mmHg}=\mathrm{millimeters} \mathrm{of}$ mercury 


\section{REFERENCES}

1. Hagen A, Albig M, Schmitz L, et al. Prenatal diagnosis of isolated foramen ovale obstruction - a report of two cases. Fetal Diagn Ther. 2005;20(1):70-3.

2. Chobot V, Hornberger LK, Hagen-Ansert S, et al. Prenatal detection of restrictive foramen ovale. J Am Soc Echocardiogr. 1990;3(1):15-9.

3. Furtado LV, Putnam AR, Erickson LK, et al. Premature Closure of the Foramen Ovale Secondary to Congenital Aortic Valvular Stenosis in a Stillborn. Fetal Pediatr Pathol. 2012;31(2):43-9.

4. Li YD, Li ZA, He YH. Premature closure or restriction of the foramen ovale: prenatal diagnosis by directional enhanced flow imaging. J Ultrasound Med. 2013;32(7):1291-4.

5. Donofrio MT, Bremer YA, Moskowitz WB. Diagnosis and management of restricted or closed foramen ovale in fetuses with congenital heart disease. Am J Cardiol. 2004;94(10):1348-51.

6. Gupta U, Abdulla RI, Bokowski J. Benign outcome of pulmonary hypertension in neonates with a restrictive patent foramen ovale versus result for neonates with an unrestrictive patent foramen ovale. Pediatr Cardiol. 2011;32(7):972-6.

7. Liu L, He YH, Li ZA, et al. Analysis of etiology, chromosome and prognosis for small left heart system development in 69 fetuses. J Matern Fetal Neonatal Med. 2016;29(3):493-503. 